\title{
ESTUDIOS
}

\section{Borges y la Novela}

La lectura más superficial de las obras en prosa de Jorge Luis Borges nos indica su interés en la novela. Podría afirmarse sin lugar a dudas que una de las constantes en la obra de Borges es esa insistencia en ilustrar las ideas con ejemplos sacados de la novelística. Y se podria añadir: en su mayor parte de la novelística anglosajona. Borges no sólo es un constante lector de esas novelas, sino también traductor de algunas de ellas; recordemos Las palmeras salvajes de William Faulkner, traducida por Borges en 1940, y el Orlando de Virginia Woolf en 1937. Además, ha prologado obras de Herman Melville, Henry James y Bret Harte, y dedicado estudios a Chesterton, Hawthorne, Joyce, Poe, Lawrence y Wells. ${ }^{2}$ Con frecuencia también cita novelas de Mark Twain y hasta de Jack London.

Los autores favoritos de Borges son aquellos que dan énfasis a lo imaginativo. Lo que no indica que desdeñe a los buenos realistas. Para

1 Prólogos a Bartlely (Buenos Aires, 1943) de Herman Melville, La bumillación de los Northmore (Buenos Aires, 1945) de Henry James y Bocetos californianos (Buenos Aires, 1946) de Francis Bret Harte.

2 "Los laberintos policiales y Chesterton", Sur, 10 (julio, 1935), 92-94. "Modos de G. K. Chesterton", Sur, 22 (julio, 1936), 47. Sobre: G. K. Chesterton, The End of the Armistice en Sur, 70 (julio, 1940), 60. "Notas sobre Chesterton", Los Anales de Buenos Aires, 20, 21, 22 (oct., nov., dic., 1947), 49-52, y en Otras inquisiciones (Buenos Aires, 1952). "Hawthorne", Cursos y Conferencias. Buenos Aires, año XVIII, vol. 35, núms. 208, 209, 210 (julio, agosto, sept., 1949), 221-240, y en Otras inquisiciones. "Joyce y los neologismos", Sur, 62 (nov, 1939), 59-61. Trad. de James Joyce, "La última hoja de Ulises", Proa, 6 (enero, 1925), 8-9. "El Ulises de Joyce", Proa, 6 (enero, 1925), 3-6, y en Inquisiciones (Bnenos Aires, 1925). "Edgar Allan Poe", La Nación (2 de oct., 1949). "Wells, el previsor", Sur, 26 (nov., 1936), 125-126. "H. G. Wells y sus parábolas", Sur, 34 (julio, 1937), 78-79. Sobre: H. G. Wells, Travals of a Republican Radical in Search of Hot Water en Sur, 64 (ene., 1940), 84. "El primer Wells", Los Anales de Buenos Aires, 9 (sept., 1946), 20-22, y en Otras inquisiciones. 
Borges la narrativa realista es la más difícil. En reciente entrevista ha confesado que piensa escribir sobre temas reales. "Pero creo -diceque el realismo es difícil, sobre todo si uno quiere hacerlo contemporáneo. Por que si yo escribo un cuento sobre tal calle o tal barrio en Buenos Aires, se descubriría inmediatamente que en tal calle o tal barrio no se habla así. De modo que para mayor comodidad conviene que el escritor busque que la acción esté algo distante en el tiempo y en el espacio. Además, el lector se siente más cómodo cuando lee algo que ha ocurrido hace tiempo, porque no está confrontándolo con la realidad. Es más cómodo para mí y para el lector. Creo que fue el error que se cometió con Don Segindo Sombra, buscar una fidelidad absoluta en el libro, que al fin de cuentas, es una suerte de elegía de la vida pastoril". ${ }^{3}$ Pero hay otra razón por la cual da preferencia a lo imaginativo. La descripción de las cosas, para Borges, no interesa. "La descripción de los objetos - dice- es muy fastidiosa. Los objetos sólo pueden interesar en función de los hombres. En rigor, se podría hacer una novela que sólo contuviera la descripción de esta silla y de esta mesa. Creo que ninguna persona leería una novela asi y nadie querría escribirla más que para entrar en la historia de la literatura como el primero que escribió una novelà en la que sólo hay una mesa." ‘

$\mathrm{El}$ interés de Borges en mundos irreales, fantásticos, le lleva a la lectura ide las novelas y los cuentos de H. G. Wells, Franz Kafka (de quien también es traductor y comentador), ${ }^{5}$ Chesterton y Hawthorne, y aun novelistas de segunda categoría como William Beckford (c. 17601:844), autor de una rara novela oriental, Vatbek (c. 1781), obra en la cual predominan los motivos fantásticos. En ella, a la vez, se hace una descripción del infierno y se pronostica "los satánicos esplendores de Thomas de Quincey, de Poe, de Baudelaire y de Huysmans". En cambio, Ias novelas de Julio Verne las califica de "razonables y nada fantásticas fantasías". Ya desde joven le interesaban las 1001 No-

${ }^{3}$ Rita Guibert" [Entrevista] "Jorge Luis Borges", Life en Español, XXXI, 5 (11 de marzo de 1968); p. 53.

4 El escritor y su obra; entrevista de Georges Cbarbonnier con Jorge Luis Borges: Trad. de Martí Soler (México: Siglo XXI, 1967), p. 47. (Título original: Entretiens avec Jorge Luis Borges. París: Editions Gallimard, 1967).

5 "Las pesadillas de Franz Kafka", La Prensa, Buenos Aires (2 de junio de 1935). Trad. de La metamorfosis (Buenos Aires, 1938). "Kafka y sus precursores", La Nación (19 de agosto de 1951) y en Otras inquisiciones.

6 "Sobre el Vathek de William Beckford", La Nación (4 de abril de 1943), $y$ en Otras inquisticiones. 
ches, obra considerada por Borges como "la primera novela por entregas del mundo".?

Desde sus años juveniles se veía Borges atraido por la narrativa, y especialmente por la novela anglosajona. ¿Por qué? He aqui una de las razones: "El psicólogo Jung -dice en el ensayo sobre Nathaniel Hawthorne- equipara las invenciones literarias a las invenciones oníricas, la literatura a los sueños. Esta doctrina no parece aplicarse a las literaturas que usan el idioma español, cliente del diccionario, de la retórica, no de la fantasía. En cambio, es adecuada a las letras de la América del Norte. Éstas (como las de Inglaterra y Alemania) son más capaces de inventar que de transcribir, de crear que de observar". 8

Como ejemplo de esa fantasía que tanto le interesa mencionaremos lo que dice de las novelas The Time Macbine y The Sense of the Past. En la primera H. G. Wells prevee hechos futuros - que no es en sí novedad - haciendo viajar al protagonista al porvenir. Pero lo que más le encanta a Borges es el motivo de que Wells se vale para pasar de lo real a lo irreal: cuando el héroe vuelve trae una flor marchita. "Más increíble que una flor celestial o que la flor de un sueño - comenta Borges- es la flor futura, la contradictoria flor cuyos átomos ahora ocupan otros lugares y no se combinan aún." 9 Por la misma razón le atrae la novela inconclusa de Henry James, The Sense of the Past, en la cual el nexo entre lo real y lo irreal no es una flor sino un retrato del siglo xvir que misteriosamente representa al protagonista. ${ }^{10}$

A pesar del tono categórico del aserto sobre la literatura en lengua española, encontramos en Borges cierta preocupación por algunas de nuestras novelas, especialmente aquellas que contienen un elemento de irrealidad. Bien conocidos son su prólogo a La invención de Morel; de su amigo Adolfo Bioy Cásares, y su reseña de La amortajada de María Luisa Bombal, ${ }^{11}$ lo mismo que los varios ensayos que le ha dedicado a la obra máxima de Cervantes. Don Quijote le atrae precisamente porque

7 El idioma de los argentinos (Buenos Aires, 1928), p. 101. Ver también "Los traductores de las 1001 noches" en Historia de la eternidad (Buenos Aires, 1936 ; 2a. ed., 1953).

8 Otras inquisiciones (Buenos Aires, 1952), p. 56.

- Ibid., pp. $18-19$.

10 Ibid., p. 19.

11 Prólogo a Adolfo Bioy Casares, La invención de Moreal (Buenos Aires, 1940). Sobre: María Luisa Bombal, La amortajada, en Sur, 47 (agosto, 1938), 80-81. Sobre: Ricardo Güiraldes, Don Segundo Sombra, en Critica, Buenos Aires (11 de agosto de 1934), y en Sur. 217-218 (nov., dic., 1952), 9-11. "Eduardo Gutiérrez, escritor realista", El Hogar, Buenos Aires (9 de abril de 1937), 12. 
allí el autor juega con la realidad. ${ }^{12}$ El interés que Borges tiene en el problema le hace destacar ese aspecto metafísico de la novela. "En realidad -dice en el ensayo 'Magias parciales del Quijote' - cada novela es un plano ideal. Cervantes se complace en confundir lo objetivo y lo subjetivo, el mundo del lector y el mundo del libro." 13 Después de citar varios ejemplos que ilustran esa confusión, añade: "Este juego de extrañas ambigüedades culmina en la segunda parte; los protagonistas del Quijote son, asimismo, lectores del Quijote" (p. 57). Hacia el fin del ensayo descubrimos el verdadero propósito de Borges al dar énfasis a esos aspectos parciales de la novela. El fin, que en verdad subraya toda su obra, es el de ilustrar la irrealidad de la existencia: "Si los caracteres de una ficción - dice- pueden ser lectores o espectadores, nosotros, sus lectores o espectadores, podemos ser ficticios" (p. 58).

No es necesario que la novela sea fantástica para que le interese a Borges. Bien conocido es su gusto por el género policial. $\mathrm{Y}$ aun por la novela realista, como lo demuestran sus ensayos sobre Don Segundo Sombra. Pero la novela realista, para ser buena, según Borges, tiene que estar estructurada en torno a las sugerencias, no los ejemplos. Para ilustrar este tipo de novela nos habla de Los idolos, del argentino Mujica Láynez, obra en la cual el protagonista es un gran poeta. "Mujica Láynez - nos dice Borges - es poeta. No un gran poeta, no es Valéry, pero sí un hombre inteligente. En todo el libro no cae nunca en el error de citar una sola línea del héroe poeta. El autor se limita a decir que su personaje ha escrito un libro: Los ídolos. Eso es todo. No cita un solo verso. Esto nos ayuda a pensar que el personaje es realmente un gran poeta. Si el autor hubiera dado un ejemplo, el lector encontraría el ejemplo bueno o malo. La ilusión estética sería reducida. La novela es bastante larga, 300 páginas. Al final uno tiene la impresión de que el personaje es un gran poeta y no ha leído uno solo de sus versos. [...] En las historias de Henry James sucede lo mismo. Se habla de grandes escritores, nada se dice de su obra salvo de una manera abstracta; o un poco irónica; o general." 14

Las anteriores observaciones atestiguan el interés que Borges tiene

12 A Cervantes le ha dedicado estos estudios: "La conducta novelística de Cervantes", Criterio, Buenos Aires, I, 2 (15 de marzo de 1928), 55-56, y en El idioma de los argentinos. Prólogo a las Novelas ejemplares (Buenos Aires, 1939). "Notas sobre el Quijote", Realidad, Buenos Aires, II, 5 (sept., oct., 1947), 234-236. "Magias parciales del Quijote", La Nación (6 de nov., 1949), y en otras inquisiciones. "Análisis del último capítulo del Quijote", Revista de la Universidad de Buenos Aires, 5a época, I, 1 (ene., marzo, 1956), 28-36.

13 Otras inquisiciones, p. 56.

14 Charbonnier, p. 45. 
en la novela. ¿Por qué, cabe preguntar, él mismo no ha escrito, o publicado, ninguna? Decimos publicado porque se menciona un libro suyo, Los naipes del tabur, en el cual trató de parecerse a Pío Baroja. Cuando estaba a punto de publicarlo se dio cuenta de sus faltas y lo olvidó. ${ }^{15}$

No hay duda que el genio creativo de Borges, como en el caso de Alfonso Reyes, se manifiesta mejor en la forma corta, ya sea la poesía lírica, el ensayo o el cuento. En este sentido ambos autores hispanoamericanos siguen las teorias de Edgar Allan Poe, quien creía que las formas cortas son estrictamente superiores, porque en el arte es indispensable la unidad de impresión. Creemos que en Borges la selección de esas formas no es una manifestación enteramente inconsciente. Al contrario, parece tener de hecho un fundamento filosófico. Con frecuencia aconseja no sólo la brevedad y la concisión estructural, sino también léxica. "Yo creo que hay palabras - ha dicho- que definen a un individuo. $Y$ las hay continuamente. ¿Por qué será esto imposible en el teatro, en una novela, cuando sucede todos los días, en el trato cotidiano de los hombres?" (Charbonnier, p. 49). Y con mayor precisión: "Y en cuanto al estilo, yo le aconsejaría más bien pobreza de vocabulärio que exceso de riqueza" (Life).

Si Borges cree, como nos dice en el ensayo "La perpetua carrera de Aquiles y la tortuga", que "la parte... no es menos copiosa que el todo" 16 ¿para qué, entonces, escribir libros voluminosos cuando se puedén expresar las mismas ideas en formas más apretadas, más a la altura del ritmo de la vida contemporánea? Eso es aparentemente lo que Borges nos dice en el Prólogo del libro Ficciones: "Desvatío laborioso y empobrecedor el de componer vastos libros; el de explayar en quinientas páginas una idea cuya perfecta exposición oral cabe en pocos minutos. Mejor procedimiento es simular que esos libros existen y ofrecer un resumen, un comentario. Así procedió Carlyle en Sarior Resartus; así Butler en The Fair Haven; obras que tienen la imperfección de ser libros también, no menos tautológicos que los otros. Más razonable, más inepto, más haragán, he preferido la escritura de notas sobre libros imaginarios. Estos son Tlön, Uqbar Orbis T'ertius; el Examen de las obras de Herbert Quain; el Acercamiento a Almotásim. La última es de 1935."17

15 Life en Español, p. 54.

16 "La perpetua carrera de Aquiles y la tortuga". Discusión (Buenos Aires, 1932), p. 150. Si bien Borges se refiere aquí a "las elevadas latitudes de la numeración", lo mismo podría decirse que ocurre en la literatura.

17 Ficciones (1935-1944) (Buenos Aires, 1944; 2a. ed. aumentada, 1956). El Prólogo suscrito el 10 de enero de 1941. 
Pero existe otra razón por la cual Borges da preferencia a las formas cortas. Si Poe creía que el cuento debe ser lo suficientemente corto para. poder ser leído sin interrupciones con el propósito de no perder el impacto que da la continuidad, Borges cree que la forma corta es portadora de un elemento dramático indispensable en la literatura. Al final de su ensayo "Historia de la eternidad" añade esta significativa nota: "El propósito de dar interés dramático a esta biografia de la eternidad, me ha obligado a ciertas deformaciones: verbigracia, a resumir en cinco o seis nombres una gestación secular." 18

Hablando del Quijote dice Borges que es sorprendente saber, en el principio del noveno capítulo, que la novela entera ha sido traducida del árabe y que Cervantes adquirió el manuscrito en el mercado de Toledo y lo hizo traducir por un morisco, a quien alojó más de mes y medio en su casa, mientras concluía la tarea. Eso le hace pensar en Carlyle, que fingió que el Sartor Resdrtus era una versión parcial de una obra publicada en Alemania por el doctor Diógenes Teufelsdroeckh; le hace pensar en el rabino español Moisés de León, autor del Zobar o Libro del Emperador, obra que fingió haber sido escrita por un rabino palestiniano del siglo IIr (Otras inquisiciones, p. 56). A los nombres de Cervantes, Carlyle y Moisés de León podríamos añadir el de Borges, que ha compuesto cuatro novelas, las cuales ha atribuido a varios autores: el $A c e r$ camiento a Almotásim al indú Mir Bahadur Alí; April March al inglés Herbert Quain; la novela circular al chino Ts'ui Pên y el nuevo Quijole al francés Pierre Menard. Mas antes de hablar de esas mininovelas de Borges volvamos por un momento a enfocar el problema de las diferencias entre novela y cuento.

Las citas anteriores tal vez hayan dejado la impresión de que Borges cree que el cuento es una novela comprimida, o como dijera Horacio Quiroga, "una novela depurada de ripios". ${ }^{19}$ Mas no es así: Borges tiene ideas bien definidas en cuanto a las diferencias esenciales entre novela $y$ cuento. En el ensayo sobre Hawthorne dice: "No soy novelista pero creo que ningún novelista ha procedido asî" (p. 65). Refiérese Borges aquí a la técnica de Hawthorne, que consiste en escribir novelas en torno a situaciones y no a personajes. Borges continúa: "Hawthorne primero imaginaba, acaso involuntariamente, una situación y buscaba, después, caracteres que la encarnaran" (p. 65). Aquí se encuentra precisamente, según Borges, la diferencia entre la novela y el cuento. El cuento tiene

18 Historia de la eternidad (Buenos Aires, 1962), p. 41. La $1^{\mathrm{a}}$ ed. es de 1936. 
su germen en la situación, la novela en el personaje. El método de Hawthorne puede producir admirables cuentos, dice Borges, "pero no admirables novelas, en donde la forma (si la hay) sólo es visible al fin y donde un solo personaje mal inventado puede contaminar de irrealidad. a quienes le acompañan" (p. 66).

En el cnsayo "El primer Wells" encontramos otras ideas de Borges. sobre el género. En la novela, dice, el argumento no es el elemento más importante. Si lo fueran todos los argumentos, no existiría el Quijote y Shaw valdría menos que O'Neill. En mi opinión - dice- la precelencía de las primeras novelas de Wells - The lsland of Dr. Moreau, verbigracia, o The Invisible Man- se debe a una razón más profunda. No sólo es ingenioso lo que refieren; es también simbólico que de algún: modo son inherentes a todos los destinos humanos".

Mas no pensemos que Borges cree que el personaje lo es todo y que las situaciones son innecesarias. No. Para Borges el personaje se define por las situaciones, pero éstas a la vez son modificadas por él. La influen:cia es recíproca. Basándose en esa idea, en el ensayo sobre The Purple Land de Hudson, traza un desarrollo de la novela así: "Del género de novelas que considero las más rudimentarias buscan la mera sucesión de aventuras, la mera variedad [...] El héroe, en ellas, es un mero sujeto, tan impersonal y pasivo como el lector [...] En otras, apenas más complejas, los hechos cumplen la función de mostrar el carácter del héroe, cuando no sus absurdidades y manías; tal es el caso de la primera parte del Quijote. En otras (que corresponden a una etapa ulterior), el movimiento es doble, recíproco; el héroe modifica las circunstancias, las circunstancias modifican el carácter del héroe. Tal es el caso de la segunda parte del Quijote, del Huckleberry Finn de Mark Twain, de The Purple Land." 20

Es obvio que el cuento no puede ser, como lo era para Quiroga, una novela sin ripios, ya que la esencial diferencia radica en el desarrollo de la situación única en aquél y en la creación del personaje a través de innumerables situaciones en ésta. Don quijote es una novela porque allí cncontramos "la venerable y satisfactoria presentación de una gran persona - dice Borges-, pormenorizada a través de doscientos trances, para que lo conozcamos mejor". ${ }^{21}$ La misma idea reaparece en el ensayo

19 "Decálogo del perfecto cuentista", en Los prenseguidores y otros cuentos (Montevideo, 1940).

20 "Nota sobre The Purple Land", La Nación (3 de agosto de 1941), 2" sec., p. 1. Recogido en Otras inquisticion:s. La cita en la p. 165.

21 "La conducta novelística de Cervantes", El idioma de los argentinos (Buenos Aires, 1928), p. 140. 
"De las alegorías a las novelas", en donde Borges hace esta observación: "[La alegoría es una] fábula de abstracciones, como la novela lo es de individuos. Las abstracciones están personificadas; por eso, en toda alegoría hay algo novelístico. Los individuos que los novelistas proponen aspiran a genéricos (Dupin es la razón, Don Segundo Sombra el gaucho); en las novelas hay elementos alegóricos." 22

Consciente de esta fundamental diferencia entre novela y cuento, Borges ha dicho que sus propias narraciones "abusan de ciertos procedimientos: las enumeraciones dispares, la brusca solución de continuidad, la contracción de la vida de un hombre a dos o tres escenas". ${ }^{23} \mathrm{Si}$ es cierto que en esta cita el autor se refiere a las narraciones coleccionadas bajo el título Historia universal de la infamia, lo mismo podría decirse de los libros que él mismo llama imaginarios, que son cuentos en los que imagina la existencia de un libro. El "Acercamiento a Almotásim", "Examen de la obra de Herbert Quain", "El jardín de senderos que se bifurcan" y "Pierre Menard, autor del Quijote" son verdaderas novelas. $^{24}$

El "Acercamiento a Almotásim", escrito en 1935, fue tal vez inspirado por la lectura de una obra de Henry James. "He leido hace poco -confiesa Borges- The Sacred Fount (1901), cuyo argumento es tan análogo. El narrador, en la delicada novela de James, indaga si en B influyen $\mathrm{A}$ o $\mathrm{C}$; en el Acercamiento a Almotásim, presiente o adivina a través de $B$ la remotísima existencia de $Z$, a quien $B$ no conoce." 25 El libro inventado por Borges que se presenta en el cuento, estructurado como reseña, es una novela policial en inglés escrita por Mir Bahadur Alí. "La editio princeps del Acercamiento a Almotásim - dice Borges bibliógrafo, aunque de libros fantásticos- apareció en Bombay, a fines de 1932. El papel era casi papel de diario; la cubierta anunciaba al comprador que se trataba de la primera novela policial escrita por un nativo de Bombay City. En pocos meses, el público agotó cuatro impresiones de mil ejemplares cada una. La Bombay Quarterly Review, la Bombay Gazette, la Calcutia Review (de Alahabad) y el Calculta Englishman, dispensaron su ditirambo. Entonces Bahadur publicó una edición ilustrada

22 "De las alegorias a las novelas", Otras inquisiciones, pp. 179-183.

23 En el Prólogo a la Historia universal de la infamia (Buenos Aires, 1935).

24 No todas las novelas de Borges tienen la forma de cuento. He aquí una que es una simple nota. En la p. 19 de la Historia de la eternidad (ed. de 1961) encontramos ésta: "Vivo, Hijo de Despierto, el improbable Robinson metafísico de la novela de Abubeker Abentofail, se resigna a comer aquellas frutas y aque. llos peces que abundan en su isla, siempre cuidando de que ninguna especie se pierda y el universo quede empobrecido por culpa de él".

25 Prólogo a Ficciones (Buenos Aires, 1956). 
que titulo The Conversation with the Man Called Al-Mu'tasim y que subtituló hermosamente: $A$ Game with Shifting Mirrors (Un juego con espejos que se desplazan.) Esa edición es la que acaba de reproducir en Londres Victor Gollancz, con prólogo de Dorothy L. Sayers y con omisión - quizás misericordiosa- de las ilustraciones. La tengo a la vista; no he logrado juntarme con la primera, que presiento muy superior. A ello me autoriza un apéndice, que resume la diferencia fundamental entre la versión primitiva de 1932 y la de 1934." ${ }^{26}$

El argumento de la novela, cuyo resumen provee Borges en el cuento, es más que sencillo, en consonancia con sus ideas sobre el género. El innominado protagonista, estudiante de derecho en Bombay, cae entre gente de la clase más vil. De golpe percibe en unos ojos una nota de ternura. Sabe que ese hombre vil es incapaz de semejante decoro y de ahí postula que en la tierra hay un hombre de quien procede esa claridad. El estudiante resuelve dedicar su vida a encontrarlo. Al cabo de los años llega a una puerta, llama y pregunta por Almotásim. "Una voz de hombre - la increíble voz de Almotásim- lo insta a pasar. El estudiante descorre la cortina y avanza. En ese punto la novela concluye" (p. 40). Almotásim cs, por supuesto, "emblema de Dios y los puntales itinerarios del héroe son de algún modo los progresos del alma en el ascenso místico" (Ibid.).

Cabe aquí apuntar que este cuento apareció primero en el libro Historia de la eternidad (1936) y por la naturaleza del tema y del contenido se le ha considerado como ensayo bibliográfico, como lo es el que le precede, cl crudito estudio sobre "Los traductores de las 1001 noches", al cual se parecen en el estilo y en la técnica, con la gran diferencia de que el último tiene su base en la realidad (las 1001 noches es un libro que cxiste), mientras que el primero es un producto de la imaginación. El Acercamiento a Almotásim sólo ha existido en la mente de Borges. Desde el punto de vista de la estética, sin embargo, ambos libros son tan reales como el Quijote de Cervantes o las Moradas de Santa Teresa. Si no lo fuera el Acercamiento a Almotásim tendriamos que negar la existencia de la literatura oral. Lo que no podemos hacer. Tan real es el Acercamiento que un lector pidió la novela a un librero de Londres.

La línea que divide lo real de lo fingido, en Borges, es tenuc. Precisamente, existe una reseña de un libro verdadero muy parecida al cuento. Trátase de la nota que apareció en la revista Sur en 1939 sobre la novela china The Golden Lotus, traducida al inglés por el sociólogo

26 "El acercamiento a Almotísim", Ficciones, p. 36. 
Clement Egerton y publicada en Londres por la editorial Routledge. La técnica de la reseña y la del cuento son idénticas. Por esa razón, y porque también nos ayuda a fijar las fuentes de otra novela de Borges, la del sinólogo Albert, que figura en el cuento "El jardín de senderos que se bifurcan", nos parece de interés para ser citada, porque también demuestra el interés de Borges en la novela china: "Quince tenaces años ha dedicado el sociólogo Clement Egerton a traducir del chino esta novela erótica y trágica. 4 nobles volúmenes abarca la traducción y vale -inaccesiblemente- 4 guineas. Por esa razón y por otra (que es la segunda guerra europea de nuestro siglo) no la tengo a la vista para redactar esta página. Conozco, sin embargo, la obra: hace un par de años he leído sin tedio ( $\mathrm{y}$ con algún horror agradable) la versión alemana de Franz Kuhn: Kin Ping Meb, Leipzig, 1929. Este volumen está asesorándome ahora. Egerton suele recurrir al remoto latín para velar las precisiones físicas del autor; el doctor Kuhn, en cambio, es de una franqueza que no excluye la obscenidad.

"La primera edición del Kin Ping Meb data del siglo diecisiete. Los hechos novelados corresponden al siglo doce, no por afición arqueológica del autor sino para exhibir con libertad las corrupciones de su tiempo. Es fama que las novelas chinas están abarrotadas de gente, como el Imperio Chino. En el Kin Ping Meh, la pululación de Volk obne Raum no es indescifrable, como en otros libros asiáticos. Por increíble que parezca, el número de dramatis personde no es infinito. La acción dura quince años, con indicación minuciosa de aniversarios, banquetes, enfermedades, peregrinaciones, procesos, agonías, coitos, divorcios, nacimientos, ceremonias nupciales y funerarias. Un adulterio, el asesinato de un hombre y la compleja y lenta retribución de los dos criminales y de su cómplice, definen acaso el tema. La brusquedad de ciertos hechos (verbigracia: los amantes deciden envenenar al marido y a las cuatro horas de esa decisión, la mujer le da una copa de arsénico) puede ser una torpeza del novelista, pero es una torpeza feliz porque confiere al crimen una sensibilidad pueril o diabólica. Dos o tres urgentes pasiones mueven las almas: el miedo, la carnalidad, la codicia. Las tres son muy sinceras.

"Numerosos poemas distraen el curso de la prosa. A veces, algún verso memorable:

La vieja lana vuelve a examina los viejos salones.

"El nombre del autor se ha perdido. El título combina los nombres 
de tres de las mujeres de la novela, pero significa también Flores de ciruelo en un jarrón de oro.

"En esta 'historia natural y social' de una familia china bajo los Sung, los rasgos sobrenaturales no faltan. Los chinos, en verdad, carecen de literatura fantástica porque todos sus libros, en algún momento, lo son." $=7$

Si la obra reseñada no existiera, esta nota sería otra novela, o mejor dicho otra mininovela, como lo es "El acercamiento a Almotásim".

No conforme con haber inventado esa novela, poco después Borges inventa un novelista a quien le atribuye varias obras narrativas. En el cuento "Examen de la obra de Herbert Quain," ${ }^{28}$ nos habla de ese autor inglés, ya muerto, a quien conoció personalmente y de quien recibió una última carta el 6 de marzo de 1939. La primera obra de Quain, The God of the Labyrinth, publicada en 1933, es como el Acercamiento a Almotásim una novela policial. Borges deplora haber prestado, irrevisiblemente, su ejemplar a una dama. Ese hecho le prohibe volver a leer la novela y por tanto no nos puede dar, después de siete años, los pormenores de la acción; pero sí se acuerda del plan de la obra. La novela tiene dos posibles soluciones, una falsa y otra verdadera. La falsa es la que da Quain. El lector astuto puede encontrar la otra, la verdadera, y sentirse así superior al detechive.

Tres años más tarde, esto es, en 1936, Quain publica su segunda novela, April March, que tiene una ingeniosa y original estructura simétrica. Los trece capítulos están organizados regresivamente. Tres de ellos se trifurcan y así en vez de una tenemos nueve novelas, cada una de tres capítulos, con el primero común a todas ellas; tres de los capítulos son, naturalmente, comunes a tres de las novelas, proceso que se repite tres veces. Así es posible tener nueve novelas de tres capítulos cada una, si bien el número total de capítulos es solamente trece. Cada una de las novelas puede ser leída de varios modos, aunque quien opta el orden cronológico "pierde el sabor peculiar del extraño libro" (p. 81). Hay en este cuento una nota de humor. "De estas novelas - dice Borges-, una es de carácter simbólico; otra, sobrenatural; otra, policial; otra, psicológica; otra, comunista; otra, anticomunista; etcétera" (p. 80).

27 Jorge Luis Borges, "Clement Egerton: The Golden Lotzs (Routledge)", Sur. IX, 60 (sept., 1939), 68-69. Existe ejemplar de esta novela en la Biblioteca del Museo Británico.

28 Se publicó primero en la revista Swr, 79 (abril, 1941), 44-48. Recogido en El jandin de senderos que se bifuran (Buenos Aires, 1941) y en Ficciones. 
Con April March Borges se adelanta a Julio Cortázar y su Rayuela. Herbert Quain es un precursor de Morelli. En el Tablero de Dirección dice Cortázar: "A su manera este libro es muchos libros, pero sobre todo es dos libros. El lector queda invitado a elegir una de las dos posibilidades siguientes. El primer libro se deja leer en la forma corriente, y termina en el capítulo $56[\ldots]$ El segundo libro se deja leer empezando por el capítulo 73 [...]. La novela de Quain, en cambio, se deja leer de nueve modos distintos. Además, en el tiempo, es regresiva: abril llega antes que marzo.

La tercera obra de Quain no es novela; es una comedia heroica, The Secret Mirror, que la crítica, dice Borges, calificó de freudiana. Esa interpretación determinó su éxito. Quain, acostumbrado al fracaso, resolvió desquitarse escribiendo otro libro, Statements (1939), colección de ocho relatos que hacen creer al lector que él los ha inventado. "Del tercero - dice Borges- yo cometí la ingenuidad de extraer Las ruinas circulares, que es una de las narraciones del libro El jardín de senderos que se bifurcan (p. 83). Asi la fuente de uno de los cuentos de Borges resulta ser el relato The Rose of Yesterday, escrito por un autor inventado por él mismo. Con esto Borges cumple con un precepto de Quain, quien afirmaba que "de las diversas felicidades que puede ministrar la literatura, la más alta era la invención" (p. 83). Para Borges, la narrativa superior es aquella en la cual el novelista hace gala de su imaginación; si la novela, como en los relatos de Quain, deja al lector participar en la creación, mejor que mejor. $\mathrm{Y}$ fijémonos que este tipo de novela abierta coincide con la que define Morelli en el capítulo 79 de Rayuela. "Parecería -apunta Morelli en una nota pedantísima- que la novela usual malogra la búsqueda al limitar al lector a su ámbito, más definido cuanto mejor sea el novelista." El novelista, continúa Morelli, debe de "hacer del lector un cómplice, un camarada de camino. Simultaneizarlo, puesto que la lectura abolirá el tiempo del lector y lo trasiadará al del autor. Así el lector podría llegar a ser copartícipe y copadeciente de la experiencia por la que pasa el novelista". Este tipo de novela, continúa el personaje de Cortázar, "no engaña al lector, no lo monta a caballo sobre cualquier emoción o cualquier intención, sino que le da algo así como una arcilla significativa, un comienzo de modelado, con huellas de algo que quizá sea colectivo, humano y no individual. Mejor, le da como una fachada, con puertas y ventanas detrás de las cuales se está operando un misterio que el lector cómplice deberá 
buscar (de ahí la complicidad) y quizá no encontrará (de ahí el com. padecimiento)." 29

Pero Borges va más allá. No satisfecho con la inventiva de los novelistas que lee, él mismo inventa sus fantásticas novelas y de ellas nos da un resumen, no menos efectivo por lo reducido. Con razón ha dicho Gore Vidal, en reciente artículo en el New York Times Book Review, que parte del genio de Borges consiste en "the lovely way he evades making books by writing reviews of novels that he has not written, demonstrating not only what he might so perfectly have done but inviting our respect for then not doing it". ${ }^{30}$

A veces, esos tesúmenes de las novelas que él no ha escrito, esas reseñas, forman parte de una obra más extensa, de una novela estructurada como April March de Quain, en donde podemos leer capítulos independientemente. El acertijo, el juego, como diría Borges, consiste en participar, en hacerse cómplice del creador y ordenarlos de diferentes maneras, hasta descubrir un orden secreto, hasta descubrir el misterio que se esconde detrás de la fachada. El lector de Borges puede intentarlo, puede ser cómplice. Y si no lo encuentra lo único que puede hacer es copadecer, ser copadeciente. Pero le quedará en los labios el placer de haber participado en la búsqueda, de haber usado la imaginación, placer supremo, según Borges.

LUIS LEAL

University of Illinois

29 Julio Cortázar, Rayuela, 3a ed. (Buenos Aires, 1966), pp. 452-454.

.30 Gore Vidal, "The Subject Doesn't Object", The New York Times Book Review (1 de sept. de 1968), p. 1. 
